\title{
Subjective evaluation of sequential spaces
}

\author{
Tingting YANG ${ }^{\mathrm{a}}$; Jian KANG ${ }^{\mathrm{a}^{*}}$ \\ a UCL Institute for Environmental Design and Engineering, The Bartlett, University College \\ London (UCL), Central House, 14 Upper Woburn Place, London WC1H ONN, United \\ Kingdom \\ ${ }^{* *}$ Corresponding author
}

\begin{abstract}
The problem of designing non-acoustic sequential spaces is drawing increasing attention from acoustic researchers and practitioners. For subjective evaluation, the effects of sound source, differences in two directions (either towards or away from a sound source), and factors correlated to acoustic comfort remain unknown. This study employed soundwalk and field measurements with a questionnaire survey of a combination of room acoustics and soundscape indicators in two comparative sequential spaces with similar spatial compositions. The sound source resulted in changes to the perceived loudness, spaciousness, and reverberation. Loudness and reverberation showed a similar tendency. Other indicators, including clarity, listener envelopment, intimacy, warmth, acoustic comfort, annoyance, directivity, and overall impression were not affected. Moving in two directions resulted in different loudness and listener envelopment in the same room, both of which were stronger when moving towards the sound source. Even under the condition of a large spatial difference and a $6 \mathrm{dBA}$ sound level difference, the difference in acoustic comfort in sequential spaces could be only about 0.1 . The correlations between acoustic comfort and room acoustics indicators varied with the direction of movements.
\end{abstract}

Keywords: Sequential spaces, Subjective evaluation, Sound source, Acoustic comfort

2020 Applied Acoustics

Date Received: 30 May 2019 Date Accepted: 7 November 2019

Available online: 10 December 2019 


\section{Introduction}

Researchers and practitioners are now giving increasing attention to the design of acoustic environments in non-acoustic spaces, such as shopping centres and atriums [13]. The aim of this study was to explore the acoustics perceptions of sequential spaces, which are defined as a series of spaces connected by openings, and have been widely applied in non-acoustic spaces design such as museums and commercial spaces, from the Baroque period onward. Sequential spaces are more communal and larger in scale when compared with single spaces, and the acoustic perceptions fall in the middle ground between room acoustics and soundscape. This is an area that has received little focus to date.

The effect of a sound source on the subjective evaluation has often been the focus of acoustic spaces design, and reliable indicators have been developed in the field of room acoustics [4,5]. Meanwhile, several previous studies on non-acoustic spaces on urban sound environments, have established indicators based on the soundscape evaluation. The common methodologies include a variety of qualitative and quantitative measurement techniques, such as having visitor evaluation based on semantic differentials [6-10], evaluating the presence of disturbing characteristics of specific sound such as traffic and agriculture [11,12], and measuring physical background noise level as a statistical level in the range $L_{A 90}$ to $L_{A 50}$. The results in urban spaces provided a solid conceptual and methodological foundation on the effects of a sound source in sequential spaces. However, large-scale sound environments are normally multi-dimensional entities composed of several audible sources [13]. Despite the existence of sequential spaces in cities, it is difficult to locate a suitable single source environment in which the effects of a sound source in sequential spaces can be explored, as is required by most researches focused on room acoustics.

Sequential spaces are characterized by their continuity, which is similar to that of urban spaces. Soundwalk is often used to evaluate urban sound environments [14]. Therefore, the method, involving regular stops was found to be more effective than the traditional approach developed by Schaferian, which involved a 1-hour walk followed by a discussion at the end [15]. There are studies relevant to the continuity of urban sound environments as expectation - that is, listeners have an expectation of how a location or source will sound. Botteldooren and De Coensel proposed that expectation is a component of soundscape perception, a factor of the reaction and the expression of the emotion [16]. Bruce and Davies also mentioned that soundscape evaluation should consider the effect of expectation. They stated that prior experiences of similar spaces and perceived loudness primarily affects the expectation of soundscape as a whole [17]. These findings have practical implications for sequential spaces. For the effect of a sound source, limited knowledge has been developed to explain whether acoustic indicators such as perceived loudness in the same room varies under different direction of movements, such as towards or away from the sound source-that is, from a quiet to noisy area, or from a noisy to quiet area.

For acoustic indicators in soundscape, acoustic comfort is one of the most frequently used parameters. Studies on urban spaces have found that background noise level is a critical factor affecting acoustic comfort [18]. Yang and Kang proposed that urban open public spaces with sound levels above $55 \mathrm{dBA}$ were seldom scored as "quiet" or "very quiet", and the average responses of levels of 60 dBA were "neither quiet, nor noisy" and it is considered as "comfortable" [19]. Previous studies in single public spaces, such as railway stations, open offices, libraries and dining spaces [20-23], explored the effects of background noise level, sound source type, and dominant sound source on acoustic comfort, but the researches discussed above showed no systematic conclusion explaining the correlations between acoustic comfort and room acoustics indicators. Therefore, changes in acoustic comfort with increases in other indicators remain unknown.

In this study, a joint methodology based on room acoustics and soundscape is 
proposed for assessing the acoustic environment in sequential spaces. The aim of the study was to explore (1) the effect of a sound source on the subjective evaluation (2) the comparison of subjective evaluation under different directions (i.e., towards or away from the sound source) and (3) the correlations among acoustic comfort, sound level, and room acoustics indicators.

\section{Methodology}

\subsection{Site selection}

Two sequential spaces, located in a major museum in London, which were connected by a concourse on the right and left on the same floor, were selected as representative sites for evaluating the effects of a sound source. Figure 1 illustrates the floor plan of these two sequential spaces showing the location of each room, concourse, and sound source. Figure $2 a$ shows the photos of the sound source which was a large-scale sound installation named Babel 2001 by Cildo Meireles. It is a permanent exhibition and formed as a cylindrical tower of hundreds of radios, which featured the sequential spaces on the right side of the concourse. The bottom tiers of the structure are made of old larger valve radios, while the upper tiers are composed of smaller mass-produced electronic radios from more recent years. Each radio is tuned to a different channel at the minimum discernible volume and all generally broadcast information, vocals, and music that are virtually unintelligible. The room containing the sound source is in indigo blue presenting a strange effect together with the sound [24]. Figure 2b shows a typical exhibition room, which composed the quiet sequential spaces on the left side of the concourse.

The number and spatial composition of the rooms, number and sizes of the coupling areas, interior design and peak hours of exhibition environment of the two sequential spaces are essentially the same as shown in Figure 1. The only difference between them is the condition of the sound source. Thus, it fulfils the comparative requirements for the research and is an ideal site for studying the effects of a sound source on subjective evaluation in occupied sequential spaces.

The left spaces were defined as the no-sound-source group used to investigate the occurrence of no sound source in sequential spaces. The right spaces were defined as the sound-source group, in which the effects of a sound source in sequential spaces were investigated. Room 1 was the sound source room. Room 5 was the entrance to the concourse, and was affected by noise in the concourse. Rooms 2, 3, 4, 6, 7, and 8 were all typical quiet exhibition spaces. The sizes of single rooms are similar, with the dimensions of approximately $6.25 \mathrm{~m}$ length, $6.25 \mathrm{~m}$ width and $4.9 \mathrm{~m}$ height.

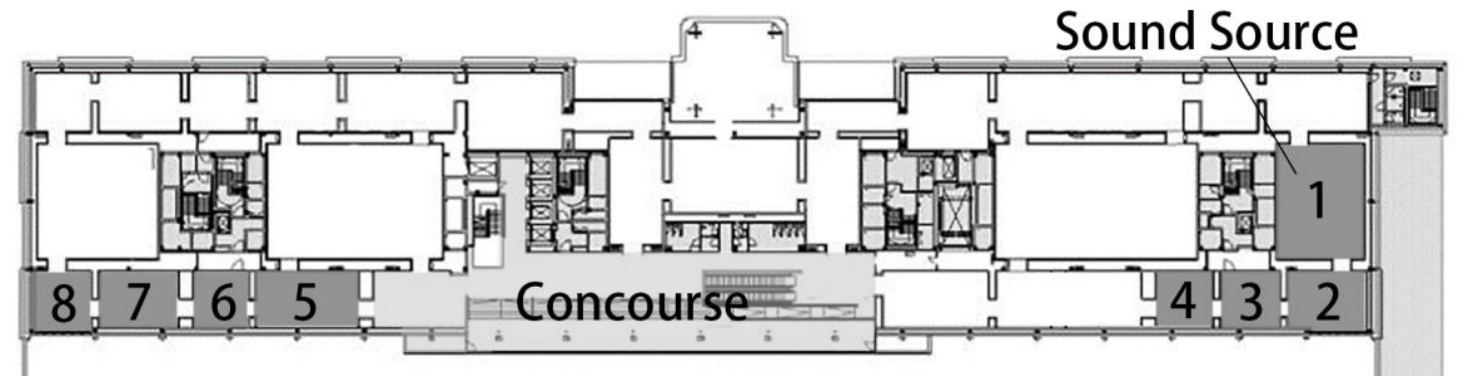

Fig. 1. Floor plan of two sequential spaces: the location of each room, concourse, and sound source. 


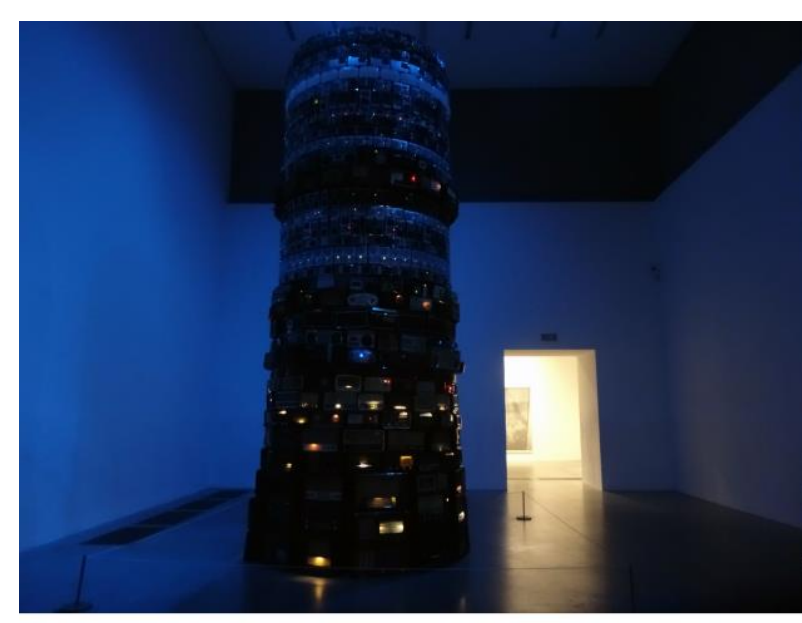

(a)

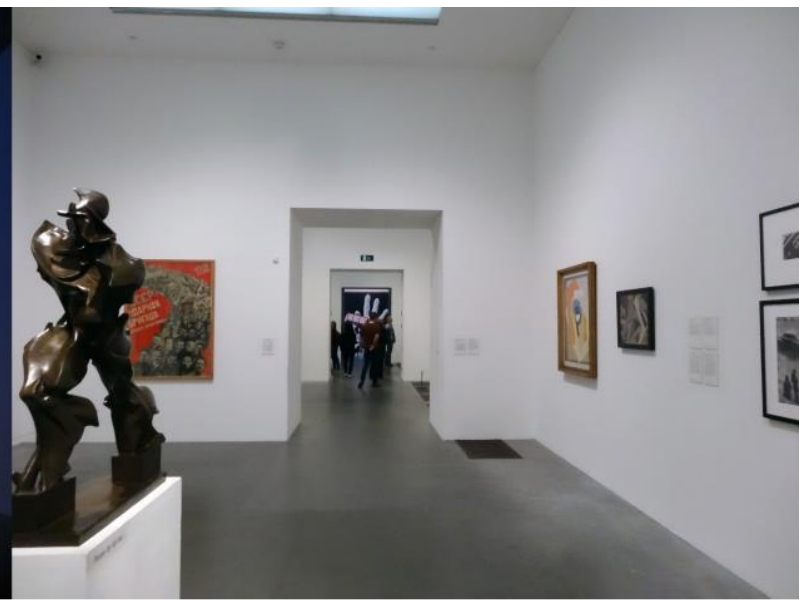

(b)

Fig. 2. Site photo. (a) Babel 2001 Sound Installation; (b) typical exhibition room.

\subsection{Questionnaire design}

As the acoustic environment in sequential spaces was assumed to be midway between room acoustics and soundscape, this was the starting point for a questionnaire study on subjective evaluation using the indicators of a combination of these two domains. For room acoustics, previous studies proposed five subjective independent dimensions: clarity, reverberant response, impression of space, intimacy, and loudness to assess the acoustic spaces, such as concert halls [25]. Beranek [26] used eight basic indicators of acoustic spaces: loudness, clarity, reverberation, spaciousness, envelopment, intimacy, warmth, and stage support. Stage support was discarded in this study since there was no performance present in the site, and therefore seven key indicators were selected. For soundscape, previous studies selected overall impression and acoustic comfort as crucial indicators to evaluate soundscapes $[27,28]$. Therefore, these two indicators were chosen to will evaluate the general soundscape. Four perceptual factors proposed by Kang [29], which are relaxation, communication, spatiality, and dynamics, have been developed to investigate the responses of listeners. Owing to the fact that this study was to be conducted in a museum, the study selected annoyance and directivity to further describe the specific context of practical architectural environments.

The assessments of questionnaire were based on perceptions of each room. Therefore, each subject was required to fill out four questionnaires. The questionnaire is composed of 12 questions - that is, (1) How loud is it? (2) How could individual notes be clearly distinguished from another? (3) How do you feel reverberant in the sound environment? (4) How do you feel spaciousness in the sound environment? (5) Are you immersed in the sound environment? (6) Are you intimate with the sound environment? (7) Are you cozy with the sound environment? (8) Can you clearly hear yourself and other sound? (9) Are you comfortable with the sound environment? (10) Can you identify the direction of the sound? (11) Are you annoyed with the sound? (12) Are you satisfied with the whole sound environment? Each single question is related to each indicator listed above. Fivepoint unipolar continuous category scales were used-that is, (1) "not at all", (2) "slightly", (3) "moderately", (4) "very", and (5) "extremely", and the verbal labelling was provided below each scale.

\subsection{Site survey}

The sound source is a permanent exhibition and lasts continuously throughout the opening hours. To confirm the appropriate in-situ time, a 1-week pilot study was conducted during the opening hours from 10:00 to 18:00 Sunday to Thursday, and 10:00 to 22:00 Friday to Saturday. It was found that although the number of visitors differed between the weekdays and weekends, within a single day it changed regularly and was 
almost the same every day, which could be classified into two conditions. There were few visitors from 10:00 to 10:30. This period can be regarded as the unoccupied condition, and it can be used to measure the acoustic parameters of the sound source. Meanwhile, the number of visitors from 12:00 to 18:00 in both sequential spaces tended to be equally distributed. Thus, the latter period can be regarded as the occupied condition, which can be used to conduct the evaluation survey and corresponding measurements.

For the effects of a sound source on each room under the unoccupied condition, the researchers arrived at the gallery at 10:00 before other visitors and measured all eight rooms. All the measurements were taken when there were no visitors present as shown in Figure 3. HEAD acoustics SQobold was used to take 1 minute binaural recordings in the centre of each space $1.65 \mathrm{~m}$ above the ground to represent the acoustic environment. Acoustic parameters including the sound level, loudness, and sharpness were collected and calculated by ArtemiS SUITE, and for temporal variability and low frequency contents, $L_{\mathrm{A} 10-} L_{\mathrm{A} 90}$ as well as $L_{\mathrm{Ceq}}-L_{\mathrm{Aeq}}$ were further calculated.

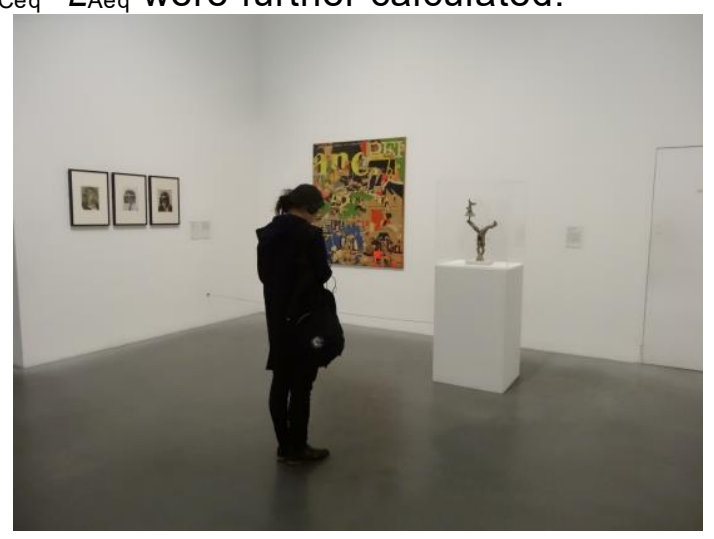

Fig. 3. Room acoustic measurements

Table 1 illustrates the results of acoustic parameters in each room under the unoccupied condition in both groups. To avoid the accident results, the measurements were taken for three times separately in three different days. The range of A-weighted equivalent sound levels of three measurements were around $6 \mathrm{dBA}$ and the variances are around $3 \mathrm{dBA}$. Thus, the final values were the means by the results of the three days. The overall range of $A$-weighted equivalent sound levels for these rooms is from 39.7 to $66.8 \mathrm{dBA}$ as shown in Table 1. The sound level is relatively low, which is in accord with normal situation of a museum or gallery. As the background noise level of the entire space is also relatively low, the sound is still audible in Room 3 and 4 . The aim of this study was to explore the acoustic perceptions of sequential spaces in reality-that is, the room near or containing the sound source is acoustically comfortable, and the room far away from the sound source is quiet, while the sound source is still distinguishable.

Table 1 Acoustic parameters under the unoccupied condition

\begin{tabular}{cccccccc}
\hline & $L_{\text {Aeq }}$ & $L_{\mathrm{A} 10}$ & $L_{\mathrm{A} 50}$ & $L_{\mathrm{A} 90}$ & $L_{\mathrm{Ceq}}$ & $L_{\mathrm{A} 10}-L_{\mathrm{A} 90}$ & $L_{\text {Ceq }}-L_{\text {Aeq }}$ \\
\cline { 2 - 7 } & {$[\mathrm{dBA}]$} & {$[\mathrm{dBA}]$} & {$[\mathrm{dBA}]$} & {$[\mathrm{dBA}]$} & {$[\mathrm{dB}]$} & {$[\mathrm{dBA}]$} & {$[\mathrm{dB}]$} \\
\hline Room 1 & $66.8 \pm 3.0$ & $68.4 \pm 2.8$ & $66.6 \pm 3.0$ & $64.8 \pm 3.1$ & $70.6 \pm 2.9$ & 3.6 & 3.8 \\
Room 2 & $60.5 \pm 3.1$ & $61.9 \pm 3.1$ & $60.3 \pm 3.1$ & $58.5 \pm 3.3$ & $64.8 \pm 3.0$ & 3.4 & 4.3 \\
Room 3 & $55.4 \pm 2.8$ & $56.5 \pm 2.8$ & $55.2 \pm 2.7$ & $54.0 \pm 2.7$ & $59.8 \pm 2.4$ & 2.4 & 4.3 \\
Room 4 & $53.6 \pm 5.8$ & $54.5 \pm 0.7$ & $53.5 \pm 0.5$ & $52.5 \pm 0.3$ & $60.6 \pm 2.4$ & 2.0 & 7.1 \\
Room 5 & $46.6 \pm 1.2$ & $48.1 \pm 1.7$ & $46.1 \pm 1.0$ & $45.1 \pm 0.5$ & $54.9 \pm 4.6$ & 3.0 & 8.3 \\
Room 6 & $42.9 \pm 2.4$ & $44.5 \pm 3.4$ & $41.8 \pm 1.2$ & $41.1 \pm 1.2$ & $55.7 \pm 6.0$ & 3.3 & 12.8
\end{tabular}




\begin{tabular}{llllllll} 
Room 7 & $42.6 \pm 4.0$ & $43.9 \pm 4.2$ & $41.3 \pm 2.4$ & $40.0 \pm 2.0$ & $53.3 \pm 5.2$ & 3.9 & 10.7 \\
Room 8 & $39.7 \pm 1.4$ & $42.0 \pm 0.9$ & $38.4 \pm 1.7$ & $36.8 \pm 1.2$ & $54.9 \pm 6.5$ & 5.2 & 15.3 \\
\hline
\end{tabular}

\subsection{Soundwalk}

The subjects were visitors who completed their visit to the exhibition space on Level 4. They were randomly approached and then asked for their consents to participate in the experiment by the researcher in the concourse on-site rather than in the quiet gallery. They were instructed to follow the experimental procedures: return to the visited spaces, walk individually following the prescribed route, and rate the subjective evaluation on the questionnaire of each marked room standing in the centre of each space. During the experiment, the researcher used the HEAD acoustics SQobold to capture a 1-minute long binaural recording of the environment close to the place where the subjects filled in the questionnaire. The acoustic parameters included the sound level, loudness, and sharpness.

The direction of the route was settled before the soundwalk. All subjects in the nosound-source group moved from rooms 5 to 8 , while the subjects in the sound-source group were further subdivided into two smaller groups. The subjects that moved from rooms 4 to 1 were defined as the towards-sound-source group, and the subjects that moved from rooms 1 to 4 were defined as the away-sound-source group. Three sets of subjective evaluations and objective measurements were collected. From each group, 36 subjects aged from 18 to 60 , gave their subjective evaluation to these sound environments, which meets the sample criterion of normal distribution that a sample size should be larger than 30 . Each of the 108 subjects completed the four questionnaires for four rooms, which amounted to 432 valid questionnaires. The investigations were conducted in January 2019 from 12:00 to 18:00 Monday to Sunday.

\section{Results}

\subsection{Effects of a sound source}

Among rooms 1, 2, 3, and 4 of the sound-source group, room 1 was the room with a sound source. For the effects of a sound source in room 1, rooms 6,7 , and 8 of the nosound-source group and rooms 4, 3, and 2 of the towards-sound-source group were selected, all of which are similar typical exhibition spaces. Table 2 shows the mean ratings and variances of loudness, reverberation, spaciousness, annoyance and acoustic comfort of these two groups according to five-point unipolar continuous category scales. For the no-sound-source group, only spaciousness was statistically significant $(p<0.05)$. For the towards-sound-source group, loudness, annoyance and acoustic comfort were very different $(p<0.01)$. Other indicators were approximate among the single rooms.

For the effects of a sound source on the sequential spaces, according to the results of multivariate analysis of variance (MANOVA) between no-sound-source group and towards-sound-source group, the results show that the mean rating differences are statistically significant for loudness and spaciousness $(p<0.01)$, and reverberation $(p<$ 0.05 ) as shown in Table 2. Unsurprisingly, for loudness, the mean ratings of towardssound-source group are $65 \%$ higher than that of no-sound-source group. For reverberation, the mean ratings of towards-sound-source group are $20 \%$ higher in room 2. For spaciousness, the mean ratings differences did not show a clear correlation with the distance from source and it could be related to other contextual factors.

Based on these results, it was concluded that the effects of the sound source among the rooms were primarily reflected in the differences in perceived loudness, annoyance, and acoustic comfort. On the other hand, the evaluation of loudness, reverberation and spaciousness changed for the effects of the sound source. The mean ratings of loudness, reverberation and annoyance shows a similar tendency with that of the distance from the sound source. 


\section{Table 2}

Mean values and variances of loudness, reverberation, spaciousness, annoyance and acoustic comfort of the no-sound-source group and towards-sound-source group.

\begin{tabular}{lllllll}
\hline & \multicolumn{2}{l}{ Towards-sound-source group } & \multicolumn{3}{l}{ No-sound-source group } \\
\cline { 2 - 7 } & Room 2 & Room 3 & Room 4 & Room 6 & Room 7 & Room 8 \\
\hline Loudness & $3.3 \pm 0.6$ & $2.4 \pm 0.6$ & $2.2 \pm 0.7$ & $2.0 \pm 0.8$ & $2.0 \pm 1.1$ & $2.0 \pm 0.8$ \\
Reverberation & $3.0 \pm 0.8$ & $2.5 \pm 1.0$ & $2.6 \pm 0.8$ & $2.6 \pm 0.8$ & $2.5 \pm 0.9$ & $2.5 \pm 0.9$ \\
Spaciousness & $3.1 \pm 0.8$ & $2.7 \pm 0.7$ & $3.0 \pm 1.0$ & $2.6 \pm 1.0$ & $3.2 \pm 1.0$ & $3.0 \pm 1.0$ \\
Annoyance & $2.0 \pm 0.7$ & $1.6 \pm 0.7$ & $1.4 \pm 0.7$ & $1.6 \pm 0.7$ & $1.6 \pm 0.8$ & $1.4 \pm 0.5$ \\
Acoustic comfort & $3.0 \pm 1.0$ & $3.2 \pm 0.9$ & $3.6 \pm 0.8$ & $3.2 \pm 0.7$ & $3.4 \pm 0.8$ & $3.5 \pm 0.8$ \\
\hline
\end{tabular}

\subsection{Difference in directions}

The effects of direction on the subjective rating, evaluated when walking through the sequential spaces, was twofold. The differences were observed among the rooms and in the same room.

The mean rating differences among the single rooms were analysed within the towards-sound-source group as well as the away-sound-source group. For the towardssound-source group, loudness, clarity, reverberation, spaciousness, listener envelopment, intimacy, acoustic comfort, and annoyance had statistical significance $(p<$ $0.05)$. For the away-sound-source group, statistical significance was only observed in the mean ratings of loudness, clarity, listener envelopment, and annoyance $(p<0.05)$. Therefore, moving in different directions results different perceptions among the rooms. It is concluded that four indicators loudness, clarity, listener envelopment, and annoyance varied throughout the sequential spaces. However, the other four indicators reverberation, spaciousness, intimacy, and acoustic comfort varied only when the subject was moving towards the source, which may be due to previous experiences in similar rooms and the ability to adapt to the perceived loudness.

The mean rating differences in the same room were identified by the comparison of towards-sound-source group and away-sound-source group. According to the results of an independent t-test, two indicators, loudness and listener envelopment are different.

Figure 4a shows that the mean ratings of loudness of towards-sound-source group is generally higher than that of away-sound-source group by $0.8,1.4,0.8$ and 0.5 in rooms 1 to 4 according to the five-point unipolar continuous category scales. In room acoustics, loudness is considered to be the perception of volume of the sound source and related to the middle frequency content. In room 1, it was dominated by "very" (67\%) for the towards-sound-source group and "moderately" (69\%) for the away-sound-source group. In room 2, it was paired with "moderately" (64\%) for the towards-sound-source group and "slightly" (53\%) for the away-sound-source group. In room 3, it was paired with "lightly" $(50 \%)$ in both groups. In room 4 , loudness was paired with "not at all" $(44 \%)$ for the towards-sound-source group and "slightly" (56\%) for the away-sound-source group.

Figure $4 \mathrm{~b}$ shows that listener envelopment is statistically significant in rooms 2 and 3 $(p<0.05)$ and mean value differences were equivalently 0.5 . In room acoustics, listener envelopment is defined as the sense of immersion related to the diffusion of the space [30-32]. In room 2, it was paired with "moderately" (33\%) for the towards-sound-source group and "slightly" (42\%) for the away-sound-source group. In room 3, it was dominated by "moderately" (39\%) for the towards-sound-source group and "slightly" (36\%) for the away-sound-source group. 


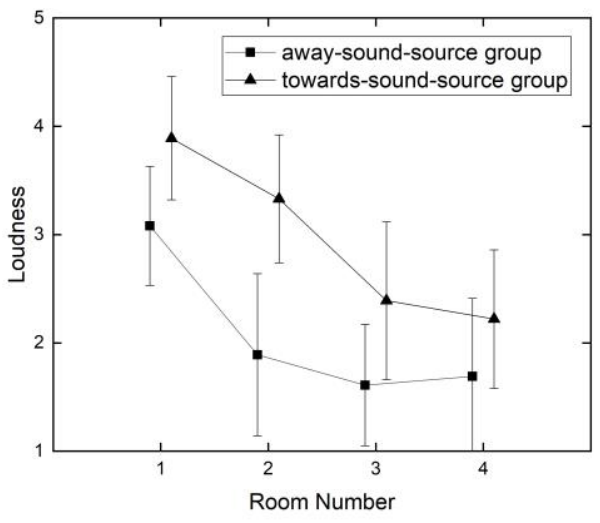

(a)

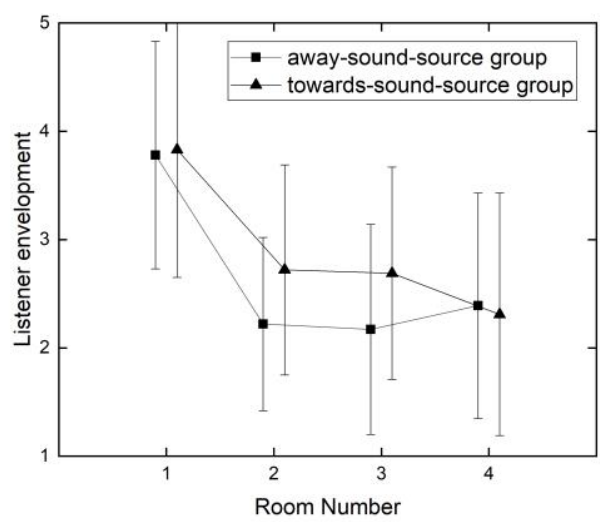

(b)

Fig. 4. Comparisons between the away-sound-source group and towards-sound-source group: (a) loudness; (b) listener envelopment.

The above results reveal that perceived loudness and listener envelopment is developed on the movements direction. When moving towards the sound source, perceived loudness was stronger than that when moving away from the sound source; this was also true of listener envelopment-that is, according to the definitions of loudness and envelopment mentioned in previous study [30-32], when the circulation is dominated by the movements towards the sound source, for perceived loudness, it is necessary to control the background noise more strictly. Similarly, when the circulation is dominated by the movement away from the sound source, for perceived listener envelopment, the diffusion should be strengthened to promote a stronger sense of immersion.

\subsection{Correlations among acoustic comfort, sound level, and room acoustics indicators}

For acoustic comfort, as detailed previously in sections 3.1 and 3.2, it was approximate in the single rooms in the no-sound-source group but statistically significant in both towards-sound-source group and away-sound-source group $(p<0.05)$. The mean ratings of four rooms in the no-sound-source group range from 3.2 to 3.4 and the overall range of A-weighted sound pressure level of four rooms under the occupied condition is 53.8 to $59.1 \mathrm{dBA}$. As a result, acoustic comfort in the no-sound-source group were outside the scope of this study. To explore the correlations with sound level and room acoustics indicators, acoustic comfort in each room was analysed for each of the two sound-source groups.

Measured equivalent sound levels (unoccupied condition) ranged from 66.8 to 53.6 $\mathrm{dBA}$ in the sound-source group, and the mean value exhibited a tendency to change gradually with a difference of $5 \mathrm{dBA}$; those in rooms 3 and 4 were essentially equivalent. Note that the variances in rooms 1,2 , and 3 were essentially equivalent, while that in room 4 was relatively small. On the other hand, statistical significance of sound level within the sound-source group (occupied condition) was high $(p<0.01)$. The mean value of sound levels exhibited a gradually changing tendency and those in rooms 3 and 4 were equivalent. The range and mean sound levels are given in Table 3 . The mean values of acoustic comfort in the towards-sound-source group and away-sound-source group are also shown in Table 3. The two tendencies were found to be generally consistent. The mean values in rooms 1 and 2 were equivalent, while that in room 4 was the highest.

Although $6 \mathrm{dBA}$ differences existed in the mean values of the sound levels in rooms 1 and 2, the mean values of acoustic comfort were equivalent. Thus, the threshold of acoustic comfort was approximately $6 \mathrm{dBA}$. In contrast, although the mean values of sound levels in rooms 3 and 4 were equivalent, the mean values of acoustic comfort were 
quite different and that of room 4 was much higher. In addition, the variance of sound levels in room 4 was $0.6 \mathrm{dBA}$, which was much smaller than that in room 3 , indicating that room 4 was less affected by the sound source than was room 3.

\section{Table 3}

Mean values and variances of sound level and acoustic comfort of the towards-sound-source group and away-sound-source group.

\begin{tabular}{llllll}
\hline & & Room 1 & Room 2 & Room 3 & Room 4 \\
\hline Lea & Unoccupied condition & $66.8 \pm 2.7$ & $60.5 \pm 2.7$ & $55.4 \pm 2.5$ & $53.6 \pm 0.6$ \\
& $\begin{array}{l}\text { Occupied condition } \\
\text { Acoustic }\end{array}$ & $68.3 \pm 2.4$ & $62.6 \pm 2.8$ & $58.8 \pm 3.0$ & $59.7 \pm 3.4$ \\
Comfort & Towards-sound-source & $3.0 \pm 1.1$ & $3.0 \pm 1.0$ & $3.2 \pm 0.9$ & $3.6 \pm 0.8$ \\
& group & & & & \\
& Away-sound-source group & $3.2 \pm 1.2$ & $3.2 \pm 1.0$ & $3.1 \pm 1.0$ & $3.3 \pm 1.0$ \\
\hline
\end{tabular}

Table 4 shows the correlations between acoustic comfort and room acoustics indicators in the towards-sound-source group and away-sound-source group. Loudness, intimacy, and warmth show were consistent for both directions. Loudness was negatively correlated with acoustic comfort in rooms 1,2 , and 3 , in which the negative coefficients in rooms 2 and 3 was larger, and was weakly correlated in room 4. Intimacy was strongly correlated with acoustic comfort with the exception of room 2. For warmth, the correlation coefficients were the highest among all indicators. In terms of indicators that were inconsistent in the two directions, clarity was strongly related to acoustic comfort when moving away from the sound source. Reverberation, spaciousness, and listener envelopment varied significantly in the two directions. These results could be further applied to the design of circulation in museums and commercial spaces and could solve critical issues in order to make the space "comfortable".

\section{Table 4}

Correlation coefficients among acoustic comfort and room acoustics indicators.

\begin{tabular}{lllllllll}
\hline & \multicolumn{3}{c}{ Towards-sound-source group } & \multicolumn{5}{c}{ Away-sound-source group } \\
\cline { 2 - 9 } & Room 1 & Room 2 & Room 3 & Room 4 & Room 1 & Room 2 & Room 3 & Room 4 \\
\hline Loudness & -0.140 & $-0.364^{*}$ & -0.253 & 0.065 & -0.155 & $-0.407^{*}$ & $-0.350^{*}$ & 0.026 \\
Clarity & -0.256 & -0.023 & 0.082 & 0.249 & $0.329^{*}$ & 0.279 & $0.396^{*}$ & 0.315 \\
Reverberation & 0.287 & 0.174 & -0.300 & -0.186 & -0.181 & $0.348^{*}$ & 0.269 & 0.328 \\
Spaciousness & 0.297 & 0.326 & 0.206 & 0.204 & 0.100 & 0.281 & $0.343^{*}$ & $0.607^{\star *}$ \\
Listener & & & & & & & & \\
envelopment & 0.280 & 0.132 & 0.136 & 0.009 & -0.102 & 0.209 & -0.10 & 0.114 \\
Intimacy & $0.419^{*}$ & 0.099 & 0.288 & $0.420^{*}$ & $0.368^{*}$ & 0.118 & 0.272 & 0.293 \\
Warmth & $0.569^{* *}$ & 0.263 & $0.352^{*}$ & $0.434^{* *}$ & $0.401^{*}$ & $0.399^{*}$ & $0.595^{\star *}$ & 0.267 \\
\hline${ }^{*} p<0.05^{* *} p<0.01$. & & & & & & &
\end{tabular}

\section{Conclusions}

To explore the acoustic environment of sequential spaces, this study selected typical cases using sound source with typical volume, which may be further studied for other cases, such as sound source with relatively higher sound level. This study employed 
room acoustics and soundscape indicators with soundwalk technique to investigate the effects of a sound source on subjective evaluation. The results are as follows:

(1) For a sound source with a sound level around $70 \mathrm{dBA}$, changes of perceived loudness, spaciousness and reverberation occurred in at least three rooms with the volume of $200 \mathrm{~m}^{3}$ individually $600 \mathrm{~m}^{3}$ entirely in sequential spaces. Perceived loudness, as expected, decreased as the distance from the source increased. Perceived reverberation decreased as the distance from the sound source increased. It is concluded that perceived reverberation is not only affected by reverberation time but also the effect of the sound source. The evidence of perceived reverberation is not clear while there is no sound source in the spaces. Perceived reverberation decreased due to the decrease of loudness.

(2) Loudness, clarity, listener envelopment, and annoyance were different among the rooms. Only when moving towards the sound source there was statistical significance for reverberation, spaciousness, intimacy, and acoustic comfort among the rooms. Loudness and listener envelopment in the same room present disparity in the two directions. Both indicators are perceived to be stronger when moving towards the sound source.

(3) Even under the condition of a large spatial difference and a $6 \mathrm{dBA}$ sound level difference, the difference in acoustic comfort in sequential spaces could be only about 0.1 according to the five-point unipolar continuous category scales. The correlations between acoustic comfort and room acoustics indicators varied with directions of movements. Indicators with consistent correlation in both directions were loudness, intimacy, and warmth. Acoustic comfort increased as loudness decreased, and the correlation between warmth and acoustic comfort is the highest for all parameters. Clarity is highly correlated with acoustic comfort in the away-sound-source group. The correlation between acoustic comfort and perceived reverberation, spaciousness, and listener envelopment were different in two directions.

In conclusion, it is suggested that the location of a sound source should be considered with respect to circulation as this will greatly improve the sound quality. For example, to improve loudness in a room in sequential spaces, the first step is to identify the dominant circulation where the room is located, and then adjust loudness via specific noise control measures, for which sound propagation phenomenon for sequential spaces needs to be better understood, along with sound propagation in long spaces, for example[33-36].

\section{Acknowledgements}

The authors express gratitude to all participants who completed the questionnaire and to the Tate Modern, London. The authors also express gratitude to Dr. Francesco Aletta, Dr. Tin Oberman and the colleagues of UCL IEDE Acoustics Group for the supports. This project has received funding from the European Research Council (ERC) under the European Union's Horizon 2020 research and innovation programme (grant agreement No. 740696 ) and is supported by Natural Science Foundation of China (51778169).

\section{References}

[1] Chen B, Kang J. Acoustic comfort in shopping mall atrium spaces-a case study in Sheffield Meadowhall. Archit Sci Rev 2004;47(2):107-114.

[2] Meng Q, Kang J, Jin H. Field study on the influence of spatial and environmental characteristics on the evaluation of subjective loudness and acoustic comfort in underground shopping streets. Appl Acoustic 2013;74(8):1001-1009.

[3] Mei $\mathrm{H}$, Kang J. An experimental study of the sound field in a large atrium. Build Environ 2012;58:91-102.

[4] Barron M. Auditorium acoustics and architectural design. London: Spon Press; 1993.

[5] Ando Y. Architectural acoustics. New York: Springer New York; 1998.

[6] Axelsson O, Nilsson ME, Berglund B. A principal components model of soundscape perception. J Acoust Soc Am 2010;128(5):2836-46.

[7] Kerrick J, Nagel D, Bennett R. Multiple ratings of sound stimuli. J Acoust Soc Am 
1969;45(4):1014-7.

[8] Kawai K, Kojima T, Hirate K, Yasuoka M. Personal evaluation structure of environmental sounds: experiments of subjective evaluation using subjects' own terms. J. Sound Vib 2004;277(3):523-33.

[9] Berglund B, Eriksen CA, Nilsson ME. Perceptual characterization of soundscapes in residential areas. Proceedings of the 17th International Congress on Acoustics. Rome, Italy, 2001.

[10] Dokmeci Yorukoglu P, Kang J. Development and testing of indoor soundscape questionnaire for evaluating contextual experience in public spaces. Building Acoustics 2017;24(4):307-24.

[11] Kogan P, Arenas J, Bermejo F, Hinalaf M, Turra B. A Green Soundscape Index (GSI): The potential of assessing the perceived balance between natural sound and traffic noise. Sci Total Environ 2018;642:463-72.

[12] Nilsson ME, Berglund B. Soundscape quality in suburban green areas and city parks. Acta Acustica united with Acustica 2006;92:903-11.

[13] Maffiolo AV, Castellengo M, Dubois D. Qualitative judgements of urban soundscapes. In: Inter-Noise 99, Fort Lauderdale, Florida, USA; 1999.

[14] Davies W, Adams M, Bruce N et al. Perception of soundscapes: An interdisciplinary approach. Appl Acoustic 2013;74(2):224-31.

[15] Bruce N, Davies W. Expectation as a factor in the perception of soundscapes. In: Euronoise, Edinburgh, Scotland; 2009.

[16] Botteldooren D, Coensel BD. Quality labels for the quiet rural soundscapes. In: Proceedings of Internoise, Honolulu, Hawaii, USA; 2006.

[17] Bruce N, Davies W. The effects of expectation on the perception of soundscapes. Appl Acoustic 2014;85:1-11.

[18] Yang W, Kang J. Acoustic comfort evaluation in urban open public spaces. Appl Acoustic 2005;66(2):211-29.

[19] Yang W, Kang J. Soundscape and sound preferences in urban squares: a case study in Sheffield. J Urban Design 2005;10(1):61-80.

[20] Kang J, Chung A, Ip G. Acoustic comfort, quality and atmosphere in 'non-acoustic' spaces: case studies in railway stations and open plan offices. In: Proceedings of the 13th international congress on sound and vibration, Vienna; 2006.

[21] Lee P, Lee B, Jeon J, Zhang M, Kang J. Impact of noise on self-rated job satisfaction and health in open-plan offices: a structural equation modelling approach. Ergonomics 2015;59(2):222-34.

[22] Dokmeci Yorukoglu P, Kang J. Analysing sound environment and architectural characteristics of libraries through indoor soundscape framework. Archives of Acoustics 2016;41(2):203-12.

[23] Chen X, Kang J. Acoustic comfort in large dining spaces. Appl Acoustic 2017; 115:155-72.

[24] Brett G. Cildo Meireles. London: Tate Publishing; 2008.

[25] Hawkes RJ, Douglas H. Subjective acoustic experience in concert auditoria. Acustica 1971:24:235-50.

[26] Beranek L. Concert and opera halls. New York: American Institute of Physics; 1996. [27] Zhang M, Kang J. Towards the evaluation, description, and creation of soundscapes in urban open spaces. Environ Plann B 2007;34(1):68-86.

[28] Kang J, Zhang M. Semantic differential analysis of the soundscape in urban open public spaces. Build Environ 2010;45(1):150-157

[29] Kang J. Urban sound environment. London: Taylor and Francis; 2007.

[30] Howard D, Moretti L. Sound and space in renaissance Venice. New Haven: Yale University Press; 2009.

[31] Morimoto M, Maekawa Z. Auditory spaciousness and envelopment. In: Proceedings of 13th ICA, Belgrade 1989;2:215-218.

[32] Bradley JS, Soulodre GA. The influence of late arriving energy on spatial impression. J Acoust Soc Am 1995;97(4):2263-2271. 
[33] Kang J. A method for predicting acoustic indices in long enclosures. Appl Acoust 1997;51(2):169-180.

[34] Kang J. The unsuitability of the classic room acoustical theory in long enclosures. Archit Sci Rev 1996;39(2):89-94.

[35] Kang J. Sound attenuation in long enclosures. Build Environ 1996;31(3):245-253.

[36] Kang J. Acoustics of Long Spaces: theory and design guidance. London: Thomas Telford; 2002. 